\title{
Prioritizing Key Factors of Executive Information Systems to Manage Data and Explain Strategy in Small and Medium Industries with AHP
}

\author{
Atena Mirhosseini Vakili (Corresponding author) \\ Dept. of Management \\ Shahid Bahonar University Of Kerman, Iran \\ E-mail: Atena.Vakili@yahoo.com
}

Habibeh Jafari

Dept. of Management

Shahid Bahonar University Of Kerman, Iran

Received: Jan. 8, 2018 Accepted: Jan. 30, 2018 Online published: Feb. 10, 2018

doi:10.5296/ijhrs.v8i1.12430

URL: https://doi.org/10.5296/ijhrs.v8i1.12430

\begin{abstract}
Historically, executive managers have less opportunity to use computer compared with other members of a company. An executive information system has become a necessity as the only effective and complete information system for managers' learning in a competitive market. Skill is the main and essential issue in solving problems especially for executive managers. To improve skills and to apply insight, company managers need to use backup equipment like executive information systems (EIS). Concerning the importance and role of determining strategy in an organization and managing its information, it is tried to explain strategy and to manage data in small and medium industries using EISs. Managers have been informed of the importance of EISs; this paper selects the best strategies for small and medium industries by collecting data and managing collected data. The research case study is small and medium industries in Golestan Province. It is attempted in this research to strengthen and analyze weaker factors by evaluating and analyzing quantitative and qualitative criteria determined to prioritize them. Data integrity is considered the best factor after reviewing factors using hierarchy model and Expert Choice software.
\end{abstract}

Keywords: executive information systems, strategy, data management, AHP 


\section{Mll Macrothink}

International Journal of Human Resource Studies

ISSN 2162-3058

2018, Vol. 8, No. 1

\section{Introduction}

In a relatively short time, executive information systems (EIS) have become important to many organizations. They provide information that supports decisions at high-level. Developing EIS is hard although it is necessary due to a combination of technical and organizational issues. Increasing competition along with development of new information technologies have caused the markets to rely on information systems. Many believe that the correct use of information technology to support decision-making is a powerful weapon to win the competition. Consequently, information system researchers and practitioners have taken decision support systems (DSS) and executive information systems (EIS) into huge consideration (Watson, 1991). EIS was first used by Rockart and Treacy in 1970 at MIT and was developed in late 1981 in many studies and articles like Harvard Business. ESS and EIS are sometimes used interchangeably. In terms of meaning and force, ESS is stronger and more extensive than EIS; both mean intelligent support systems in management. Watson states that EIS is an executive computer system that relates commands to internal and external information and creates success. Effective data management is often mentioned as a key to the success because data of EIS is very intensive. EIS experts assure us that EIS is correct and that combined data of various resources is regarded as a main concept (Rockart, 1982). Numerous methods have been proposed to present strategies and to manage data. In the present study, data hierarchy analysis method is used for new management and strategy. Prioritizing EIS key factors and their importance, this method highlights strong points of information; a new strategy can be created by managing information obtained from AHP correctly. Special importance of EIS can be identified in this new strategy which results in a more effective trend in an industry.

\section{An Introduction to Information Systems}

\subsection{Definition of Management Information Systems}

Despite various definitions presented for information systems, the most comprehensive one is in Dictionary of American Librarianship Association:

"A complete system designed to produce, collect, organize, store, market and distribute information in a working area or an institution." Managerial aspects of EIS data management are generally more problematic than the technical aspects. Moreover, many EISs have their own databases and are separated from operational bases due to several reasons: technical hardness and difficulty associated with the EIS, differences in definitions of data and report cycles among data sources and considerations for running a system like slow response time of many organizations develops data sources and data trade centers support EIS (Mackeracher, 1996). 


\subsection{Information Systems in Organizational Pyramid}

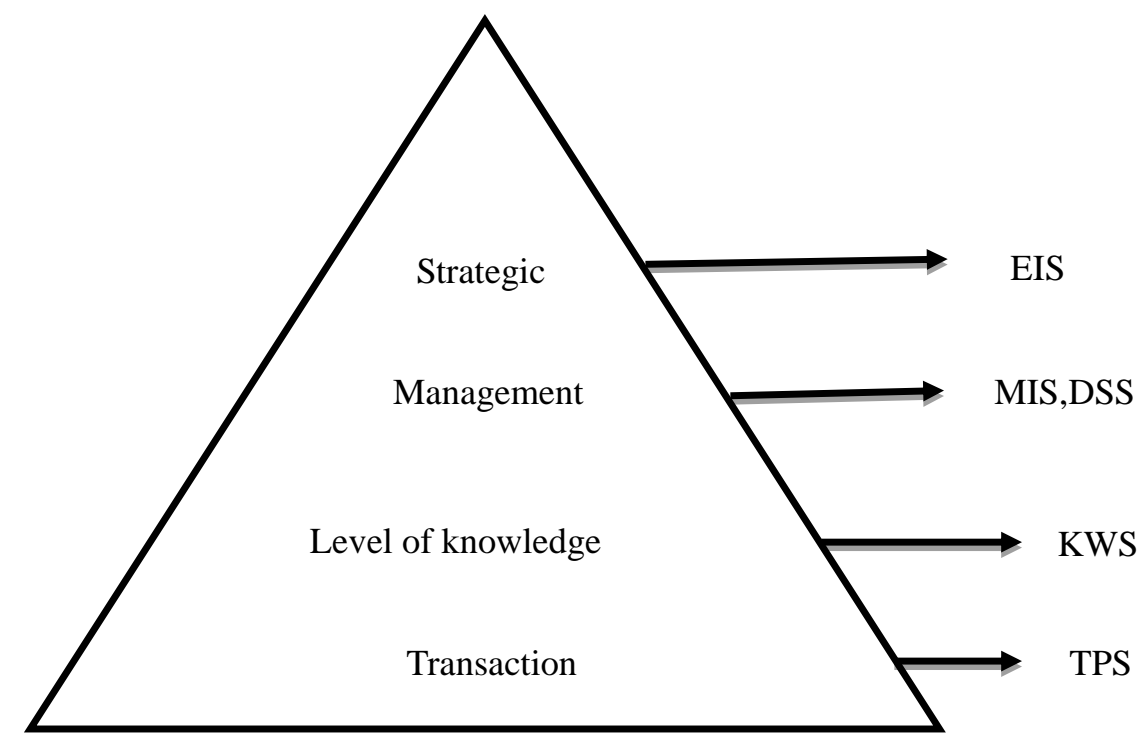

Figure 1. Information systems in organizational pyramid

Executive information systems (EIS) are flexible tools that provide broad and deep information such as news, regulations, and competitive analysis for use in executive decision making. These systems were created to address the needs of executives and support strategic decision making through scanning, analysis, and interpretation functions that continue to expand in their power and scope (Yu \& et al, 2015). EIS is a special type of DSS which helps decision making in high organizational levels. EIS shows senior managers an exact image of organization's performance and a summary of activities of rivals. It is easy to work with this system which presents information in a way that it is easily receivable (e.g. graph, chart etc.) (Vandenbosch \& Higgins, 1994).

\subsection{EIS Special Specifications}

7 main issues have been presented for EIS data management: 1) data requirements, 2) data sources, 3) data security and access control, 4) data ownership, 5) data standards, 6) data integrity and 7) data storage and retrieval. Of them, data integrity is felt to be the most important and difficult one by managers.

1) Data requirements:

Determining EIS requirements includes understanding nature of executive work and their hardness, and difficulties in determining their requirements; analysts have limited understanding of data executive requirements and some experience in developing an EIS. Applications are rarely used and must be removed or modified. In addition, tracking systems can be used by removing unusual activities to strengthen security.

2) Data sources:

Developing an EIS discovers many problems which are considered insignificant. One of the main EIS sources is working personnel who collect and process information. 
3) Data ownership:

An EIS obtains most data directly from lower levels of the organization (i.e. normal chain passes through command).

4) Data security and access control:

To many companies, security is a main consideration in designing EISs.

5) Data standards:

Most EIS managers believe that data standardization is important due to some reasons: 1) increased electronic data application, 2) global trade development which requires data communication among scientific boundaries and 3) continuous trend of company reconstruction.

6) Data integrity:

Data integrity is critical to the success of an EIS because even an event of failure provides precious information which can result in disastrous loss of executives' confidence in the system.

7) Data storage and retrieval:

Generally, faster and more exact data response time is more reliable. Although data proximity increases local storing capacity, it increases expenses(Liang \& Hung, 1997).

\subsection{The Following List Shows the Main Barriers to EIS Applications}

1- Difficulty in identifying user's needs.

2- User's resistance to the use of computers.

3- Lack of user's commitment.

4- Lack of support of other sectors.

5- Lack of system builders.

6- Lack of senior manager's support.

7- Lack of suitable development tools.

8- Difficulty in creating good examples.

9- No known successful cases

Success of an EIS depends on many factors which include providing support for data management process and explaining strategy. Strategy management consists of five stages: organizational goals, environment verification, formulation of strategies, application of strategy and strategic control(Andrews, 1987).

Lack of suitable information to support strategic management is an important issue to senior managers and can have disastrous effects on organizational performance. An EIS has the 
potential to provide information that supports strategic management. Such a system can improve efficiency and usefulness of managers who use it (Meade \& et al, 1997).

\section{Strategic Management Process}

Strategic management is the essence and base of executive management. This process means "major organization development, advances in strategies, structures and systems necessary to achieve such growth and organizational systems necessary for effective management, codification, and formulation of a complex strategy with a certain structure. Some of this information is potentially provided by an EIS. Strategic management literature provides a wide variety of strategic management models which are, in many ways, similar to each other. They determine how objectives of an organization, policies, implementation methods, and operations of an organization can be integrated (Mintzberg \& et al,1976).Regardless of the complexity and uncertainty inherent in any environment, information processing (a firm's ability to adapt to existing market conditions) is largely dependent on its ability to process relevant market information effectively. Thus, the executive information system is crucial to certain strategic decisions which may instrumental to the growth of strategic effectiveness in organization (Yin, 2015).

\subsection{Application of Strategy and EIS}

When strategies are adjusted, they must be put into action. Activities related to these applications keep commitments to organizational objectives and obtain results. For example, executive managers are in charge of managing executive operations including political and economic aspects of changes. Two important activities in this step are based on the facts that (1) since managers must understand activities that organizational units and people need in order to apply strategies, they must describe the work, related executive methods and policies and appropriate and suitable way of guiding work and (2) they must identify suitable people with good skills and correct training for the given work. This stage requires assigning work responsibilities, coordinating the efforts of various experts in an organizational and establishing an organizational structure to facilitate distribution of tasks within the organization. One EIS is often created under the following circumstances: managers who have time limit for analysis and managers who have difficulty telling their necessary information completely. EIS needs rapid growth. Interest, support, and successful progress of information systems are not easy for senior managers of every company. Information systems that support senior managers are not older than one decade (Lorgnge, 1998) .Nord and Nord (1995) emphasize that vice chairman and middle managers use theses systems more than senior managers. Putting these facts together, it can be explained that successful application is not considered a good point and successful usages may not be as what we expect. Moreover, critical success or failure factors used for other information systems may not necessarily be used for information systems of managers.

\subsection{Literature Review}

Vandenboush and Higinz conducted a three-step study to measure EIS learning; they also had a comprehensive review of individual learning, mental models, education, and mental 
and managerial writings (ling, 2007). Sooter showed that "Common aspect must be proportional to managers' management style" and it must be considered a criterion by an EIS (Sauter, 1999). Mccracher and Magolda described learning priorities in a mental progress continuum which was an important executive step in designing a comprehensive learning environment (Magolda, 1992). Campbell claimed that an independent, separate, or autonomous style was effective for most men and a continuous, communicative, or dependent style was good for most women. Providing an online method for EIS user, Sun and Newton configured information environment based on selection environment to retrieve information (Vowler, 1995). Mcbrier claimed that presence of a balanced statistical research, partial data analysis and a case study on information systems (in organizations and institutions) which could apply combined qualitative analysis in common quantitative analysis are very essential (McBride, 1995).

\section{Analytical Hierarchy Process (AHP)}

Analytic hierarchy process (AHP) was introduced by Saaty (1980), and it facilitates an approach to allocate the relative importance of evaluation items based on weights of criteria (Wang, 2016). A theoretical framework proposed by Saaty in this method can be used as a useful tool in making decisions about complex problems. The AHP is extended by incorporating the basic concepts of fuzzy sets theory.This method is popularly known as fuzzy AHP. The fuzzy AHP has been developed, in which the pair-wise comparisons in the judgment matrix are fuzzy numbers. The decisions are evaluated in a systematic manner through subjective ratings such as 'between three and five times less important' and 'approximately three times more important (Abdullah, 2015) .

Application of this method is based on three principles:

A) establishing a ranking structure and format for the problem

B) establishing priorities through paired comparisons (in the form of a final substitution rate)

C) establishing logical consistency of measurements

In addition to calculating consistency rate of judgments, analyzing result sensitivity is possible in this method by changing information. These two cases have prioritized AHP over other survey methods.

AHP is usable in both individual level and group level. In fact, one of AHP advantages is that it provides a suitable structure and framework for group partnership in making decisions (Asgharpour, 2008).

Traditional AHP technique analyzes managerial issues using systematic methods and is based on accurate and definite data. However, complexity and uncertainty found in many problems cause decision makers not to make definite and final decisions and judgments and cause them to make vague and fizzy judgments(Ling, 2007).

As mentioned before, to select the most suitable option in AHP method, total agreement towards indexes and options is used. In these models, definite AHP presuppose that the final 
point about an item is expressed as a real number; in real situations, however, this assumption may be false. In this case, fuzzy AHP can be suitable (Azar, 2002).

\subsection{Weighting Model Indexes Using AHP}

In this step which is one of the most critical steps in implementation of the model, AHP is used to calculate the weight of strategy evaluation indexes (Amy, 2008).

Make the hierarchical structure of decision factors, each decision maker is asked to express relative importance of each pair of two-by-two decision factor in one level with a nine-degree scale. Collect scores of this two-by-two comparison and create matrixes of paired comparisons for every $\mathrm{K}$ of decision maker.

Stability analysis: priority of factors can be compared by calculating values and vectors.

$$
\mathrm{A} \cdot w=\lambda_{\max } \cdot w
$$

Where:

$\mathrm{W}$ is specific or weight vector of matrix $\mathrm{A}$ and $\lambda_{\max }$ is the highest specific amount of matrix A. Then, consistency index of matrix is checked to ensure consistency of judgments in paired comparisons. Consistency index (CI) and consistency ratio (CR) are defined as follows (Saaty, 1994) :

$$
\begin{gathered}
C I=\frac{\lambda_{\max }-n}{n-1} \\
C R=\frac{C I}{R I}
\end{gathered}
$$

where:

$\mathrm{N}$ is number of compared items in matrix and $\mathrm{RI}$ is random index.

That is, consistency index related to paired comparison matrix which is randomly prepared with a similar size. Saaty suggested that high ceiling of CR values was 0.05 for $\mathbf{3} \times \mathbf{3}$ matrix, 0.08 for $4 \times 4$ matrix and 0.1 for bigger matrixes. If consistency test is failed, decision makers must modify initial values in two-by-two comparison matrix (Beheshtian, 2001).

In paired comparisons, there is one DM for every panel. However, in decision making process there may be more than one DM all of which must be considered in the panel. In these cases of group decision making, geometric mean for matrix elements can be used.

$$
\begin{gathered}
\mathrm{D}=\left\|\mathrm{a}_{\mathrm{ij}}=\frac{\mathrm{W}_{\mathrm{i}}}{\mathrm{W}_{\mathrm{j}}}\right\| \\
\mathrm{a}_{\mathrm{ij}}^{\prime}=\left(\prod_{\mathrm{l}=1}^{\mathrm{k}} \mathrm{a}_{\mathrm{ij} 1}\right)^{\frac{1}{k}} \quad ; 1=1,2, \ldots, \mathrm{k} \quad ; \mathrm{i}, \mathrm{j}=1,2, \ldots, \mathrm{n} ; \mathrm{i} \# \mathrm{j}
\end{gathered}
$$

If every DM must have more effect on decisions due to its responsibility and specialty, a 


\section{Ml Macrothink}

International Journal of Human Resource Studies

weight $\left(\mathrm{W}_{1}\right)$ can be given to its viewpoints and the following relation can be used:

$$
a_{i j}^{r}=\left(\prod_{i=1}^{k} a_{i j 1}^{w_{1}}\right)^{\frac{1}{12 w_{i}}}
$$

Where:

$\mathrm{N}$ is number of compared items in matrix and $\mathrm{RI}$ is random index.

That is, consistency index related to paired comparison matrix which is randomly prepared with a similar size. Saaty suggested that high ceiling of CR values was 0.05 for $3 \times 3$ matrix, 0.08 for $4 \times 4$ matrix and 0.1 for bigger matrixes. If consistency test is failed, decision makers must modify initial values in two-by-two comparison matrix (Saaty, 2007).

Table 1. Random index (RI)

\begin{tabular}{cccccccccccccc}
\hline $\mathrm{N}$ & 1 & 2 & 3 & 4 & 5 & 6 & 7 & 8 & 9 & 10 & 11 & 12 & 13 \\
$\mathrm{RI}$ & $0 / 58$ & $0 / 90$ & $1 / 12$ & $1 / 24$ & $1 / 32$ & $1 / 41$ & $1 / 45$ & $1 / 19$ & $1 / 51$ & $1 / 48$ & $1 / 56$ & $1 / 57$ & $1 / 59$ \\
\hline
\end{tabular}

Table 2. Paired comparison scales

\begin{tabular}{l|l|l|l|l|l}
\hline $\begin{array}{l}\text { Comparing } \\
\text { importance } \\
\text { of } \mathrm{i} \text { and } \mathrm{j}\end{array}$ & $\begin{array}{l}\text { Equal } \\
\text { importance }\end{array}$ & $\begin{array}{l}\text { Little importance } \\
\text { of } \mathrm{i} \text { on } \mathrm{j}\end{array}$ & $\begin{array}{l}\text { High importance } \\
\text { of } \mathrm{i} \text { on } \mathrm{j}\end{array}$ & $\begin{array}{l}\text { Very high } \\
\text { importance of } \\
\mathrm{i} \text { on } \mathrm{j}\end{array}$ & $\begin{array}{l}\text { Absolute } \\
\text { importance of } \\
\mathrm{i} \text { on } \mathrm{j}\end{array}$ \\
\hline $\begin{array}{l}\text { Importance } \\
\text { degree }\end{array}$ & 1 & 3 & 5 & 7 & 9 \\
\hline
\end{tabular}

In determining importance factor of indexes, in addition to using existing data, information, and opinions, holding structured meetings, and designing special questionnaires of managers' opinions at all levels of organization, customers, employees and all people who have a role in strategic planning process are of great importance.

Weights related to indexes are first determined and then are judged by experts using a questionnaire. In a case they are confirmed, they become a criterion for evaluating the effectiveness of strategies. If they are rejected, they will be reviewed in decision making process and the related weights will be modified.

Collecting experts' viewpoints using a questionnaire, paired comparisons were made among decision elements. Weights related to strategies and their evaluation indexes are calculated using AHP process relations described completely in this article.

\section{Research Methodology}

Kackar believes that many intangible executive features are not calculable in a single continuous unit; it is due to data measurement limitations or executive nature. Managerial aspects of EIS data management are generally more problematic than technical aspects (Kackar, 1987). Identifying priority of key factors of EISs to manage data and explain strategies in small and medium industries first started with library studies using hierarchical 


\section{Macrothink}

International Journal of Human Resource Studies

ISSN 2162-3058

2018, Vol. 8, No. 1

analysis and continued with interviews with the experts; finally a questionnaire was prepared. In this questionnaire, identified factors were determined and experts were asked to recognize priority of each factor at different levels in the form of a paired comparison matrix. The decision making tree is shown as follows:

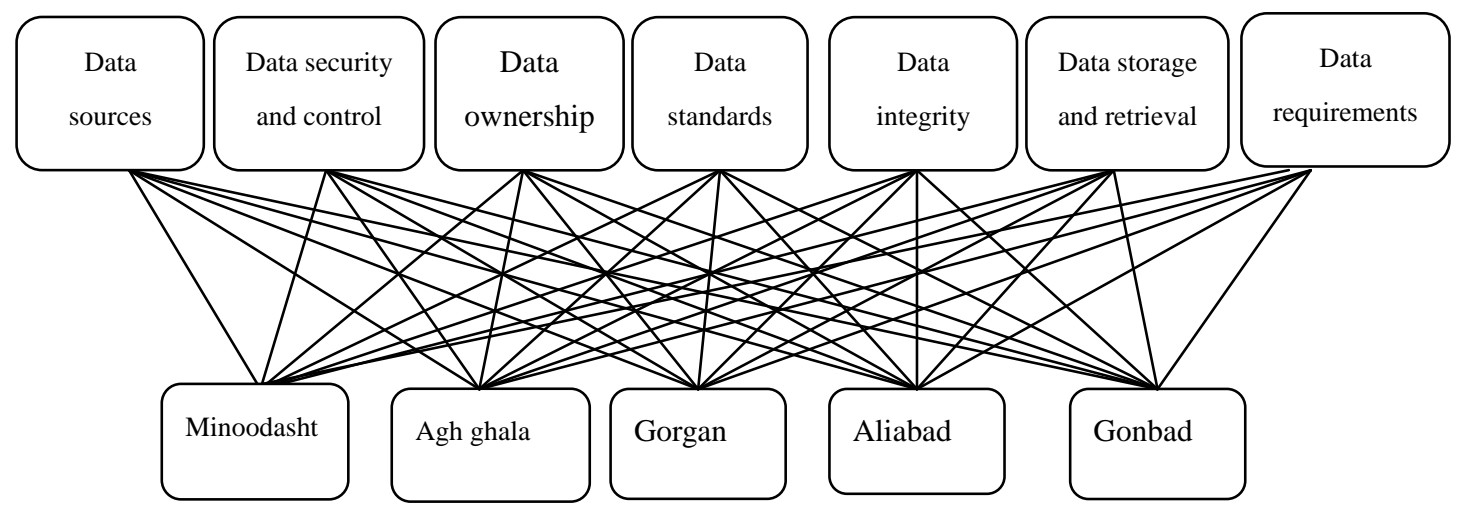

Figure 2. Decision-making tree of key factors of executive information systems

Table 3. Identification criteria of the key factors of executive information systems

\begin{tabular}{l|l|l|l|l|l|l}
\hline $\begin{array}{c}\text { Data } \\
\text { resources }\end{array}$ & $\begin{array}{c}\text { Data security } \\
\text { and control }\end{array}$ & $\begin{array}{c}\text { Data } \\
\text { ownership }\end{array}$ & $\begin{array}{c}\text { Data } \\
\text { standards }\end{array}$ & Data integrity & $\begin{array}{c}\text { Data storage } \\
\text { and retrieval }\end{array}$ & $\begin{array}{c}\text { Data } \\
\text { requirements }\end{array}$ \\
\hline I7 & I6 & I 5 & I 4 & I 3 & I 2 & I 1 \\
\hline
\end{tabular}

Table 4. Towns studied in Golestan Province

\begin{tabular}{c|c|c|c|c}
\hline Aliabad & Minoodasht & Gorgan & Gonbad & Agh Ghala \\
\hline E & D & C & B & A \\
\hline
\end{tabular}

Table 5. Matrix of paired comparisons of criteria

\begin{tabular}{|c|c|c|c|c|c|c|c|c|}
\hline Priority of criteria)I( & I1 & $\mathrm{I} 2$ & I3 & I4 & I5 & I6 & I7 & Weights \\
\hline I1 & 1 & 2 & 1 & 6 & 1 & 4 & 2 & $0 / 224$ \\
\hline $\mathrm{I} 2$ & & 1 & $1 / 2$ & 4 & $1 / 2$ & 1 & 4 & $0 / 131$ \\
\hline I3 & & & 1 & 3 & 4 & 2 & 3 & $0 / 253$ \\
\hline I4 & & & & 1 & 2 & $1 / 2$ & $1 / 4$ & $0 / 039$ \\
\hline I5 & & & & & 1 & 2 & 2 & $0 / 165$ \\
\hline I6 & & & & & & 1 & 4 & $0 / 114$ \\
\hline I7 & & & & & & & 1 & $0 / 073$ \\
\hline
\end{tabular}

In this table, inconsistency rate is 0.9 and since it is less than 0.9 , it is acceptable and doesn't need to be removed.

Table 6. Matrix of paired comparisons of choices based on criterion (I1)

\begin{tabular}{|c|c|c|c|c|c|c|c|}
\hline Criterion )I1( & A & B & $\mathrm{C}$ & $\mathrm{D}$ & $\mathrm{E}$ & Weights & \\
\hline A & 1 & 3 & $1 / 2$ & 2 & 4 & $0 / 257$ & \\
\hline B & & 1 & $1 / 2$ & $1 / 4$ & 3 & $0 / 107$ & \\
\hline $\mathrm{C}$ & & & 1 & 3 & 6 & $0 / 377$ & \\
\hline $\mathrm{D}$ & & & & 1 & 5 & $0 / 211$ & \\
\hline $\mathrm{E}$ & & & & & 1 & $0 / 047$ & $\mathrm{RI}=0.08$ \\
\hline
\end{tabular}




\section{Macrothink}

International Journal of Human Resource Studies

ISSN 2162-3058 2018, Vol. 8, No. 1

In this table, inconsistency rate is 0.08 and since it is less than 0.08 , it is acceptable and doesn't need to be removed.

Table 7. Matrix of paired comparisons of choices based on criterion (I2)

\begin{tabular}{|c|c|c|c|c|c|c|c|}
\hline Criterion )I2( & $\mathrm{A}$ & $\mathrm{B}$ & $\mathrm{C}$ & $\mathrm{D}$ & $\mathrm{E}$ & Weights & \\
\hline $\mathrm{A}$ & 1 & $1 / 4$ & $1 / 3$ & 2 & 4 & $0 / 141$ & \\
\hline B & & 1 & 2 & 4 & 4 & $0 / 409$ & \\
\hline $\mathrm{C}$ & & & 1 & 3 & 6 & $0 / 287$ & \\
\hline $\mathrm{D}$ & & & & 1 & 5 & $0 / 115$ & \\
\hline $\mathrm{E}$ & & & & & 1 & $0 / 048$ & $\mathrm{RI}=0.9$ \\
\hline
\end{tabular}

In this table, inconsistency rate is 0.9 and since it is less than 0.9 , it is acceptable and doesn't need to be removed.

Table 8. Matrix of paired comparisons of choices based on criterion (I3)

\begin{tabular}{|c|c|c|c|c|c|c|}
\hline Criterion ) I3( & $\mathrm{A}$ & B & $\mathrm{C}$ & $\mathrm{D}$ & $\mathrm{E}$ & Weights \\
\hline A & 1 & 3 & $1 / 4$ & 1 & 4 & $0 / 189$ \\
\hline B & & 1 & $1 / 2$ & $1 / 4$ & 3 & $0 / 107$ \\
\hline $\mathrm{C}$ & & & 1 & 3 & 6 & $0 / 434$ \\
\hline $\mathrm{D}$ & & & & 1 & 5 & $0 / 224$ \\
\hline $\mathrm{E}$ & & & & & 1 & $0 / 045$ \\
\hline
\end{tabular}

In this table, inconsistency rate is 0.9 and since it is less than 0.9 , it is acceptable and doesn't need to be removed.

Table 9. Matrix of paired comparisons of choices based on criterion (I4)

\begin{tabular}{|c|c|c|c|c|c|c|}
\hline Criterion )I4( & $\mathrm{A}$ & $\mathrm{B}$ & $\mathrm{C}$ & $\mathrm{D}$ & $E$ & Weights \\
\hline $\mathrm{A}$ & 1 & 1 & 2 & 4 & $1 / 3$ & $0 / 204$ \\
\hline B & & 1 & 3 & 5 & 3 & $0 / 366$ \\
\hline C & & & 1 & 2 & 5 & $0 / 107$ \\
\hline D & & & & 1 & $1 / 4$ & $0 / 056$ \\
\hline$E$ & & & & & 1 & $0 / 267$ \\
\hline
\end{tabular}

In this table, inconsistency rate is 0.9 and since it is less than 0.9 , it is acceptable and doesn't need to be removed.

Table 10. Matrix of paired comparisons of choices based on criterion (I5)

\begin{tabular}{|c|c|c|c|c|c|c|c|}
\hline Criterion )I5( & $\mathrm{A}$ & B & $\mathrm{C}$ & $\mathrm{D}$ & $\mathrm{E}$ & Weights & \\
\hline $\bar{A}$ & 1 & 4 & 2 & 1 & 2 & $0 / 293$ & \\
\hline B & & 1 & $1 / 2$ & $1 / 4$ & 3 & $0 / 109$ & \\
\hline $\mathrm{C}$ & & & 1 & $1 / 3$ & 4 & $0 / 179$ & \\
\hline $\mathrm{D}$ & & & & 1 & 3 & $0 / 341$ & \\
\hline$E$ & & & & & 1 & $0 / 078$ & $\mathrm{RI}=0.9$ \\
\hline
\end{tabular}

In this table, inconsistency rate is 0.9 and since it is less than 0.9 , it is acceptable and doesn't need to be removed. 


\section{Macrothink}

International Journal of Human Resource Studies

ISSN 2162-3058 2018, Vol. 8, No. 1

Table 11. Matrix of paired comparisons of choices based on criterion (I6)

\begin{tabular}{|c|c|c|c|c|c|c|}
\hline Criterion )I6( & A & B & $\mathrm{C}$ & D & $\mathrm{E}$ & Weights \\
\hline $\mathrm{A}$ & 1 & 9 & 3 & 3 & $1 / 2$ & $0 / 491$ \\
\hline B & & 1 & $1 / 7$ & $1 / 3$ & $1 / 3$ & $0 / 040$ \\
\hline $\mathrm{C}$ & & & 1 & 2 & 3 & $0 / 166$ \\
\hline $\mathrm{D}$ & & & & 1 & $1 / 2$ & $0 / 094$ \\
\hline E & & & & & $1 / 4$ & $0 / 209$ \\
\hline
\end{tabular}

In this table, inconsistency rate is 0.1 and since it is less than 0.1 , it is acceptable and doesn't need to be removed.

Table 12. Matrix of paired comparisons of choices based on criterion (I7)

\begin{tabular}{|c|c|c|c|c|c|c|c|}
\hline Criterion $) \mathrm{I} 7($ & $\mathrm{A}$ & $\mathrm{B}$ & $\mathrm{C}$ & $\mathrm{D}$ & $\mathrm{E}$ & Weights & \\
\hline A & 1 & 3 & 1 & 2 & 2 & $0 / 281$ & \\
\hline B & & 1 & $1 / 2$ & $1 / 5$ & $1 / 3$ & $0 / 446$ & \\
\hline $\mathrm{C}$ & & & 1 & 3 & 2 & $0 / 146$ & \\
\hline $\mathrm{D}$ & & & & 1 & 1 & $0 / 047$ & \\
\hline $\mathrm{E}$ & & & & & 1 & 0/079 & $\mathrm{RI}=0.08$ \\
\hline
\end{tabular}

In this table, inconsistency rate is 0.08 and since it is less than 0.08 , it is acceptable and doesn't need to be removed.

Table 13. Ranking a city based on AHP technique

\begin{tabular}{ccc}
\hline Choice & Weight & Rank \\
\hline A & $0 / 304$ & 1 \\
B & $0 / 255$ & 2 \\
C & $0 / 207$ & 3 \\
D & $0 / 147$ & 4 \\
E & $0 / 087$ & 5 \\
\hline
\end{tabular}

Hierarchical consistency rate: 0.09

\section{Conclusions}

Lack of a senior EIS information system and lack of data management can result in organizational decline. To manage data and to announce a strategy to make an industry more effective, it is important to have a strong EIS, to obtain all indexes of EIS and finally to manage these indexes continuously and optimally. In this research, key factors of a strong EIS were first introduced in small and medium industries in an industrial town of Golestan. Then, importance level of each factor was achieved by hierarchy analysis model (data integrity in this research). Since other weights of key factors were achieved in this research, managing these factors can make industries more effective.

\section{References}

Abdullah, L., \& Zulkifli, N. (2015). Integration of fuzzy AHP and interval type-2 fuzzy DEMATEL: An application to human resource management. Expert Systems with Applications, 42, 4397-4409. https://doi.org/10.1016/j.eswa.2015.01.021

Amy H. I. et al. (2008). A fuzzy AHP and BSC approach for evaluating performance of IT 
department in the manufacturing industry in Taiwan, Expert Systems with Applications, 34, 96-107. https://doi.org/10.1016/j.eswa.2006.08.022

Andrews, K. R. (1987). The concept of the corporate strategy, Irwin, Homewood, IL.

Asgharpour, M. J. (2008). Multi-criterion decision making. Tehran University.

Azar, A., \& Faraji, H. (2002). Fuzzy management science. Iranian Center of Studies and Productivity.

Beheshtian, M., \& Abolhasani, H. (2001). Management information systems. Tehran University

Kackar, R. N. (1987). Taguchies Quality Philosophy: Analysis and commentary, Quality Assurance, 13, 65-71

Liang, T. P., \& Hung, S. Y. (1997). DSS and EIS applications in Taiwan, 10(4), 303-315.

Lorgnge, P. (1998). Strategy implementation: the new realities, long Rang planning, 18-30.

Mackeracher, D. (1996). Making sense of adult learning. Toronto, Ontario: culture concepts.

Magolda, M. (1992). Knowledge and reasoning in college: gender-related patterns in students intellectual development. sanfrancisco, CA: jossey-Bass.

McBride, N. (1995). The roles of executive information system in organization: an inter pretive analysis. Proceedings of the 28th Hawaii inter national conference on system sciences, $110-119$.

Meade, L. M. \& et al. (1997). Justifying strategic alliances and partnering a prerequisite for virtual enterprising, Omega, 29-43. https://doi.org/10.1016/S0305-0483(96)00034-5

Mintzberg, H., \& Raisinghani, D. (1976). A. theoret, the structure of "unstructured", decision processes, Administrutive science Quarterly, 12(2), 267-275.

Nord, J. H., \& Nord, D. (1995). Executive information system: a study and comparative analysis, Information And Management, 29(2), 95-106. https://doi.org/10.1016/0378-7206(95)00013-M

Rockart, A. C., \& Treacy, M. E. (1982). The CEO Goes online, Harward business Review, 80-82.

Saaty, T. L. (1994). How to make a decision: the analytic hierarchy Process. Inter faces, 24(6). https://doi.org/10.1287/inte.24.6.19

Sauter, V. (1999). Decision support system .New York: John Wiley and sons.

Vandenbosch, B., \& Higgins, C. (1994). The measurement of learning from executive information system. Proceedings of the 27th Hawaii international conference system sciences, 572-585. https://doi.org/10.1109/HICSS.1994.323461

Vowler, J. (1995). BPR projects fail to deliver. computer weekly, June(22), 28. 


\section{Macrothink}

International Journal of Human Resource Studies

ISSN 2162-3058 2018, Vol. 8, No. 1

Wang, X. et al. (2016). How smart is your tourist attraction? Measuring tourist preferences of smart tourism attractions via a FCEM-AHP and IPA approach Tourism Management, 54, 309-320. https://doi.org/10.1016/j.tourman.2015.12.003

Wanga, L. et al. (2007). Selection of optimum maintenance strategies based on a fuzzy analytic hierarchy process, Int. J. Production Economics, 107, 151-163. https://doi.org/10.1016/j.ijpe.2006.08.005

Watson, H. J. et al. (1991). Executive information system a framework for development and a surevy of current practice, MIS Quarterly, 15(1), 13-30. https://doi.org/10.2307/249431

Yin, C. Y. (2015). Measuring organizational impacts by integrating competitive intelligence into executive information system .Journal of Intelligent Manufacturing, 1-15. https://doi.org/10.1007/s10845-015-1135-4

$\mathrm{Yu}, \mathrm{C}$. P. et al. (2015). The roots of executive information system development risks, Information and Software Technology, 68, 34-44. https://doi.org/10.1016/j.infsof.2015.08.001

\section{Copyright Disclaimer}

Copyright for this article is retained by the author(s), with first publication rights granted to the journal.

This is an open-access article distributed under the terms and conditions of the Creative Commons Attribution license (http://creativecommons.org/licenses/by/4.0/). 